\title{
An Emerging Translational Model to Screen Potential Medicinal Plants for Nephrolithiasis, an Independent Risk Factor for Chronic Kidney Disease
}

\author{
San-Yuan Wu, ${ }^{1}$ Jui-Lung Shen, ${ }^{2,3}$ Kee-Ming Man, ${ }^{4,5,6,7}$ Yuan-Ju Lee, ${ }^{8}$ \\ Huey-Yi Chen, ${ }^{1,9}$ Yung-Hsiang Chen, ${ }^{1,9}$ Kao-Sung Tsai, ${ }^{1,9}$ Fuu-Jen Tsai, ${ }^{1,9}$ \\ Wei-Yong Lin, ${ }^{1,9}$ and Wen-Chi Chen ${ }^{1,9}$ \\ ${ }^{1}$ School of Chinese Medicine, Graduate Institute of Chinese Medicine, Graduate Institute of Integrated Medicine, College of Chinese \\ Medicine, Research Center for Chinese Medicine and Acupuncture, China Medical University, Taichung 40402, Taiwan \\ ${ }^{2}$ Center for General Education, Feng Chia University, Taichung 40724, Taiwan \\ ${ }^{3}$ Department of Dermatology, Taichung Veterans General Hospital, Taichung 40705, Taiwan \\ ${ }^{4}$ Department of Medicinal Botanicals and Health Applications, Da-Yeh University, Changhua 51591, Taiwan \\ ${ }^{5}$ Department of Anesthesiology, Tungs' Taichung Harbor Hospital, Taichung 43304, Taiwan \\ ${ }^{6}$ Department of Life Sciences, National Chung Hsing University, Taichung 40227, Taiwan \\ ${ }^{7}$ Graduate Institute of Geriatric Medicine, Anhui Medical University, Hefei 230032, China \\ ${ }^{8}$ Department of Urology, National Taiwan University Hospital, Taipei 10002, Taiwan \\ ${ }^{9}$ Departments of Medical Research, Obstetrics and Gynecology, Dermatology, and Urology, China Medical University Hospital, \\ Taichung 40447, Taiwan
}

Correspondence should be addressed to Wei-Yong Lin; linwy@mail.cmu.edu.tw and Wen-Chi Chen; wgchen@mail.cmu.edu.tw

Received 30 May 2014; Accepted 16 June 2014; Published 6 July 2014

Academic Editor: Mohamed Eddouks

Copyright (c) 2014 San-Yuan Wu et al. This is an open access article distributed under the Creative Commons Attribution License, which permits unrestricted use, distribution, and reproduction in any medium, provided the original work is properly cited.

\begin{abstract}
Pharmacological therapy for urolithiasis using medicinal plants has been increasingly adopted for the prevention of its recurrence. A Drosophila melanogaster model developed for translational research of urolithiasis was applied to evaluate agents with potential antilithic effects and calcium oxalate $(\mathrm{CaOx})$ formation. Potential antilithic herbs were prepared in a mixture of food in a diluted concentration of 5,000 from the original extract with $0.5 \%$ ethylene glycol (EG) as the lithogenic agent. The control group was fed with food only. After 3 weeks, flies ( $n \geq 150$ for each group) were killed using $\mathrm{CO}_{2}$ narcotization, and the Malpighian tubules were dissected, removed, and processed for polarized light microscopy examination of the crystals. The crystal formation rate in the EG group was $100.0 \%$. In the study, 16 tested herbal drugs reached the crystal formation rate of $0.0 \%$, including Salviae miltiorrhizae, Paeonia lactiflora, and Carthami flos. Scutellaria baicalensis enhanced CaOx crystal formation. Two herbal drugs Commiphora molmol and Natrii sulfas caused the death of all flies. Our rapid screening methods provided evidence that some medicinal plants have potential antilithic effects. These useful medicinal plants can be further studied using other animal or human models to verify their effects.
\end{abstract}

\section{Introduction}

Urolithiasis is a common urologic disorder with high prevalence and recurrence [1-4]. It has been reported that kidney stones are a significant and independent risk factor for chronic kidney disease in the general population. An overall prevalence from $9.6 \%$ to $6.5 \%$ and a 5 -year recurrence rate of
$34.7 \%$ are observed in Taiwan $[5,6]$. Owing to high recurrence, various treatment modalities are available; however, currently, the prevention of the recurrence of urolithiasis remains a challenge [7].

Pharmacological therapy for urolithiasis using medicinal plants in traditional Chinese medicine (TCM) has been arising for the prevention of its recurrence [8-12]. A single 
agent or formula such as Takusha, Wulingsan, and Desmodium styracifolium were reviewed by Miyaoka and Monga. They concluded that TCM has promising roles in urinary stone prevention [13]. However, over 300 different types of medicinal plants exist according to the record of "Ben Cao Bei Yao (本草備要; Complete Essentials of the Materia Medica)," a famous TCM pharmacology book. Few of them were studied for the antilithic effect, although potential effects were recorded. One of the possible causes for this is the lack of rapid tools to extensively study these abundant herbal drugs [14-16].

The development of novel translational research technologies and approaches is of central importance for successful complementary and alternative (CAM) research. Recently, we have developed a fruit fly (Drosophila melanogaster) model for translational research of urolithiasis and applied this model to the evaluation of agents that may have potential antilithic effect [17-19]. The Malpighian tubule of the fruit fly has a function similar to the human kidney [20-23].

Calcium oxalate $(\mathrm{CaOx})$ crystal formation can be seen 3 weeks after the addition of lithogenic agents (ethylene glycol (EG)) to the food. The crystals were easily observed under polarized microscopy, and the crystal formation rate can then be evaluated [17-19]. For example, a test for the effect of melamine on crystal formation in Drosophila was performed. The results indicate that the administration of melamine caused crystal formation in a mixture of $\mathrm{CaOx}$, calcium phosphate, uric acid, and melamine crystals [18]. In a previous study by $\mathrm{Ho}$ et al., it was found that potassium citrate could prevent crystal formation in EG-induced $\mathrm{CaOx}$ nephrolithiasis in Drosophila. No inhibitory capability of commercial citrate-containing juice was observed for $\mathrm{CaOx}$ crystal formation in the Malpighian tubules of the fly [19]. Therefore, this model can be further used as a rapid screening method to test any drugs that have a potential antilithic effect. Since kidney stones are a significant and independent risk factor for chronic kidney disease in the general population. In this study, we attempted to use this emerging translational model to rapidly screen the potential antilithic medicinal plants.

\section{Materials and Methods}

2.1. Animal Model. We used wild-type male D. melanogaster fed with $0.5 \%$ EG as lithogenic group and D. melanogaster fed without lithogenic agent as control group in this study for the evaluation of $\mathrm{CaOx}$ crystal formation [17-19]. In brief, flies were bred in plastic vials containing a medium of yeast, corn syrup, and agar. Flies were maintained under a condition of $25^{\circ} \mathrm{C}, 60 \%$ humidity, and a $12 \mathrm{~h}$ light-dark cycle. Potential antilithic herbs were prepared in a mixture of food in a diluted concentration of 5,000 from the original extract with $0.5 \%$ EG (Sigma, USA) as the lithogenic agent. The control group of flies was fed with food only. After 3 weeks, flies $(n \geq 150$ for each group) were killed by $\mathrm{CO}_{2}$ narcotization, and the Malpighian tubules were dissected, removed, and processed for examination of the crystals by polarized light microscopy.
2.2. Screening of Potential Antilithic Medicinal Plants. The extracts of herbs were provided by Sun Ten Pharmaceutical Co. (Taichung, Taiwan). We then selected potential herbs according to the record of "Ben Cao Bei Yao." A total of 80 herbs were tested in this study (Table 1). Tested herbal drugs were considered to have an antilithic effect if the crystal formation rate was zero. The total death of flies in the tested group was not considered for the positive effect.

2.3. Observation of $\mathrm{CaO} x$ Crystal Formation. The Malpighian tubules were dissected and immediately observed under normal and polarized white light using an Olympus BX51 optical microscope (Japan) after crystal induction. We photographed the relevant crystal aspects using a Kodak ProImage 100 film with scales (USA).

2.4. Statistical Analysis. For each group, data are presented as the crystal formation rate (\%). All calculations were performed using Statistical Package for Social Sciences (SPSS for Windows, version 8.0, SPSS Inc., Chicago, IL, USA).

\section{Results}

3.1. CaOx Crystal Formation Rate. The crystal formation rate in EG and control groups was $100.0 \%$ and $10.2 \%$, respectively. Positive $\mathrm{CaOx}$ crystal formation can be seen in the Malpighian tubules of flies (Figure 1). In the first study, 16 tested herbal drugs reached the crystal formation rate of 0\% (Table 1), namely, Salviae miltiorrhizae (number 11, 丹 參), Paeonia lactiflora (number 19, 白药藥), Carthami flos (number 21, 紅花), Corydalis yanhusuo (number 29, 延胡索), Imperata cylindrica (number 35, 白茅根), Prunus armeniaca (number 42, 杏仁), Eclipta prostrata (number 43, 旱蓮 草), Artemisia argyi (number 46, 艾葉), Plantago asiatica (number 48 and its seed number 50, 車前子), Lonicera japonica (number 49, 忍冬藤), Polygoni cuspidati (number 52, 虎杖), Astragalus membranaceus (number 67, 黃老), Wolfiporia cocos (number 70, 获苓), Scutellaria baicalensis (number 76, 黃芩), and Angelicae sinensis (number 77, 當歸).

Two herbal drugs caused the death of all flies in this study. These were Commiphora molmol (number 44, 沒藥) and Natrii sulfas (number 47, 芒硝), and death may be due to their toxicities.

In contrast, Cuscuta chinensis (number 78, 菟絲子) enhanced $\mathrm{CaOx}$ crystal formation in the Malpighian tubules, reaching the crystal formation rate of $100 \%$.

\section{Discussion}

In our survey, 16 herbs were determined to be successful antilithic herbs. Our results provide valuable information for future studies regarding antilithic herbs suitable for the prevention of urolithiasis. In an ongoing study, Carthami flos has been further studied for its potential antilithic effects, and a positive result was obtained when it was applied to a rat model [11].

Abundant herbal drugs with antilithic effects that are used for treatment are available in TCM books [17, 24-27]. 
TABLE 1: Potential antilithic medicinal plants/agents and rate of calcium oxalate crystal formation in Malpighian tubules of male Drosophila.

\begin{tabular}{|c|c|c|}
\hline Common name & Latin name/chemical name & Crystal formation (\%) \\
\hline Control & & 10.20 \\
\hline $0.5 \% \mathrm{EG}$ & & 100.00 \\
\hline Chinese hawthorn & Crataegus pinnatifida & 36.36 \\
\hline Dogwood & Cornus officinalis & 62.50 \\
\hline Chinese yam & Dioscorea opposite & 45.45 \\
\hline Sichuan lovage rhizome & Ligusticum chuanxiong & 27.27 \\
\hline Pseudoginseng & Panax notoginseng & 33.33 \\
\hline Common bur reed & Sparganium stoloniferum & 45.45 \\
\hline Szechwan chinaberry & Melia toosendan & 30.00 \\
\hline Rhubarb & Rheum rhabarbarum & 25.00 \\
\hline Morinda root & Morindae officinalis. & 33.33 \\
\hline Trogopterus dung & Faeces trogopterori & 7.14 \\
\hline Salvia root & Salviae miltiorrhizae & 0.00 \\
\hline Cowherb seed & Semen vaccariae & 20.00 \\
\hline Achyranthes root & Achyranthis bidentatae & 30.00 \\
\hline Costus root & Aucklandia lappa & 20.00 \\
\hline Kidney tea & Clerodendranthus spicatus & 30.00 \\
\hline Akebia caulis & Caulis akebiae & 10.00 \\
\hline Licorice root & Glycyrrhiza uralensis & 40.00 \\
\hline Largehead atractylodes & Atractylodis macrocephalae & 80.00 \\
\hline White peony root & Paeonia lactiflora & 0.00 \\
\hline Dried rehmannia root & Rehmannia glutinosa & 30.00 \\
\hline Safflower & Carthami flos & 0.00 \\
\hline Dark plum fruit & Fructus mume & 60.00 \\
\hline Bupleurum & Bupleurum chinensis & 54.55 \\
\hline Magnolia bark & Magnolia officinalis & 50.00 \\
\hline Peach kernel & Semen persicae & 25.00 \\
\hline Immature bitter orange & Citrus aurantium & 50.00 \\
\hline Fructus aurantii & Citrus aurantium Fructus & 40.00 \\
\hline Wolfberry & Lycium barbarum & 66.67 \\
\hline Corydalis tuber & Corydalis yanhusuo & 0.00 \\
\hline Walnut & Juglans regia & 30.00 \\
\hline Herba lysimachiae & Lysimachia christinae & 9.00 \\
\hline Common monkshood root & Aconitum carmichaelii & 40.00 \\
\hline Chinese clematis & Clematis chinensis & 28.57 \\
\hline Fructus evodiae & Evodia rutaecarpa & 18.18 \\
\hline Lalang grass rhizome & Imperata cylindrica & 0.00 \\
\hline Cinnamon & Cinnamomum cassia & 8.33 \\
\hline Ginger & Zingiber officinale & 10.00 \\
\hline Chingma abutilon seed & Abutilon indicum & 41.67 \\
\hline Taiwan angelica root & Angelica dahurica & 25.00 \\
\hline Cynanchum glaucescens & Cynanchi stauntonii & 8.33 \\
\hline Blackened swallowwort root & Cynanchum atratum & 9.09 \\
\hline Almond & Prunus armeniaca & 0.00 \\
\hline Yerbadetajo herb & Eclipta prostrata & 0.00 \\
\hline Myrrh & Commiphora molmol & - \\
\hline Common peony root & Paeonia veitchii & 64.00 \\
\hline Argy wormwood leaf & Artemisia argyi & 0.00 \\
\hline Glauber's salt & Sodium sulfate & - \\
\hline Plantaginis seed & Plantago asiatica $\mathrm{L}$. & 0.00 \\
\hline Honeysuckle stem & Lonicera japonica & 0.00 \\
\hline
\end{tabular}


TABle 1: Continued.

\begin{tabular}{|c|c|c|}
\hline Common name & Latin name/chemical name & Crystal formation (\%) \\
\hline Plantaginis & Plantago asiatica & 0.00 \\
\hline Frankincense & Boswellia sacra & 11.00 \\
\hline Giant knotweed & Polygoni cuspidati & 0.00 \\
\hline Honeysuckle flower & Lonicera japonica Thunb. & 18.00 \\
\hline Polyporus & Polyporus umbellatus & 75.00 \\
\hline Talcum powder & Pulvis talci & 40.00 \\
\hline Taraxacum & Taraxacum officinale & 57.14 \\
\hline Membrane of chicken gizzard & N/A & 66.67 \\
\hline Common rush & Juncus effusus & 28.57 \\
\hline Carapax trionycis & Triony $x$ sinensis & 57.14 \\
\hline Rehmanniae preparata root & Rehmannia glutinosa & 44.44 \\
\hline Bazheng powder & $\mathrm{N} / \mathrm{A}$ & 33.00 \\
\hline Fringed pink & Dianthus superbus & 75.00 \\
\hline Water plantain & Alisma canaliculatum & 25.00 \\
\hline Coix seed & Coix lacryma-jobi & 75.00 \\
\hline Pilose asiabell root & Codonopsis pilosula & 33.33 \\
\hline Himalayan teasel root & Dipsacus asperoides & 100.00 \\
\hline Milkvetch root & Astragalus membranaceus & 0.00 \\
\hline Cape jasmine fruit & Gardenia jasminoides & 50.00 \\
\hline Rhizoma curcumae & Curcuma phaeocaulis & 50.00 \\
\hline Indian buead & Wolfiporia cocos & 0.00 \\
\hline Sweetgum fruit & Liquidambar formosana & 20.00 \\
\hline Rice paperiant pith & Tetrapanax papyriferus & 100.00 \\
\hline Combined spicebush root & Lindera aggregata & 40.00 \\
\hline Corn stigma & Zea mays L. & 66.00 \\
\hline Common knotgrass & Polygonum aviculare $\mathrm{L}$. & 50.00 \\
\hline Baical skullcap root & Scutellaria baicalensis & 0.00 \\
\hline Angelica root & Angelicae sinensis & 0.00 \\
\hline South dodder seed & Cuscuta chinensis & 100.00 \\
\hline Scurfpea fruit & Psoralea corylifolia & 25.00 \\
\hline Dwarf lilyturf tuber & Ophiopogonjaponica & 50.00 \\
\hline
\end{tabular}

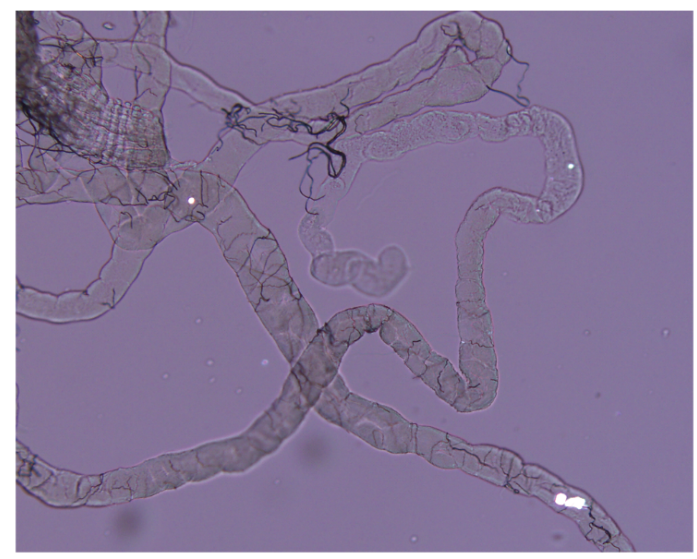

(a)

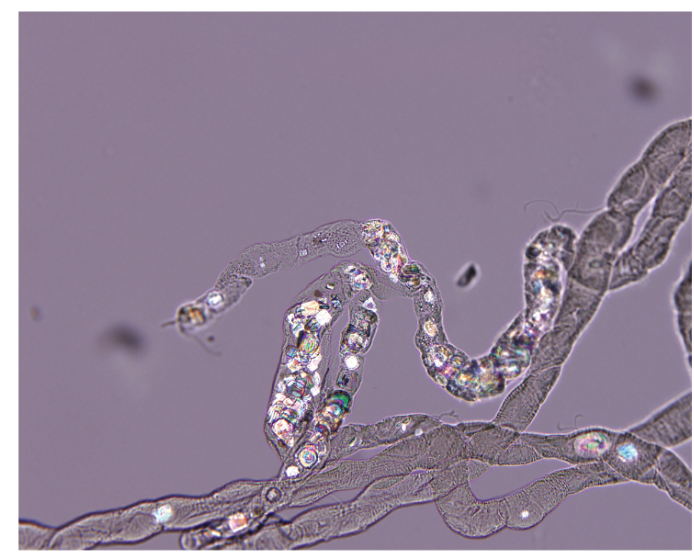

(b)

FIGURE 1: EG-induced CaOx crystal deposition in the Malpighian tubules. The images show representative polarized microscopy for the (a) control flies and (b) the flies with $0.5 \%$ EG-induced crystal formation in Malpighian tubules. 
Some drugs have been studied using in vitro models such as nucleation, crystal aggregation, and crystal growth [23]. Conventionally, rats have been used as animal models to study the crystal formation rate in the kidney. The application of a large number of herbal drugs requires the use of a large number of animals, leading to high cost. Our study used a large number of animals and large-scale drug lists to reach significant results that provide valuable data for the study of antilithic effects. The use of the fruit fly has been cited as a potential new animal model to study urolithiasis and has been proven to be effective [20,23].

Cuscuta chinensis has several pharmacological effects, particularly in the genitourinary tract, including replenishing the kidney essence and improving sperm motility, kidney deficiency, urinary frequency, and erectile dysfunction [28, 29]. Its effectiveness was reported by Pan et al.; they showed that an ethanol extract of Cuscuta chinensis was effective on Th1 and Th2 cell functions and that it could be safely used as an adjuvant in a mice model [30]. A patent (publication number CN102579706 A; 2012) has been used for the application of Cuscuta chinensis as part of a formula for treating urolithiasis in China. This formula reached an effective rate of $70 \%$. We also selected Cuscuta chinensis as a potential antilithic agent in this study. However, the treatment detail of this formula remains unclear because this formula is not composed of a single herb. Based on our results, Cuscuta chinensis exerted adverse effects that completely enhanced crystal formation. Therefore, further studies will need to be performed to clearly identify the effects of individual components by other means.

Natrii sulfas is a TCM drug made from crystals refined from the processed Glauber's salt, which is crystalline hydrated form of sodium sulfate. It mainly contains $\mathrm{Na}_{2} \mathrm{SO}_{4} \cdot 10 \mathrm{H}_{2} \mathrm{O}$. In a study on rats, Natrii sulfas was suggested to have a protective effect on ischemia-induced brain edema and to improve the physiological symptoms [31]. It has been recorded in the TCM books that Natrii sulfas can cause the lysis of urinary stones, but it caused the death of flies in this study. Although these herbal drugs may have potential antilithic effects, they have been revealed to have toxic effects; therefore, they cannot be used as a single agent for the treatment of urolithiasis. Conventionally, TCM uses a formula with a combination of several drugs to reduce the toxic effect. These drugs should be carefully reconsidered if used clinically.

Myrrha is a resin made from the Commiphora molmol tree. Studies on Myrrha revealed analgesic and antiinflammatory effects in the treatment of various diseases associated with inflammatory pain, such as arthritis, obesity, microbial infection, wound, pain, fractures, tumor, and gastrointestinal diseases $[32,33]$. In this study, we selected Myrrha because it is used for spasm and pain relief. However, in our study, Myrrha caused the death of flies. Some side effects have been associated with Myrrha, such as bleeding tendency, damage to the kidney, or stomach pain $[34,35]$. The use of smaller dosage as part of the herbal formula has been suggested. The limitation of this herb is that it caused the death of flies. Further studies using smaller dosage may elucidate the effect of Myrrha on the treatment of urolithiasis.
An advantage of our study is that a large number of types of herbs could be rapidly screened within a short period using a large number of animals. The limitations of this study include crude water extracts only, limited dosage control, and invertebrate animal model, which may have important anatomical differences compared with mammals. However, this model has proven to be reliable, since several scientific research articles have been published with this stable fly model.

\section{Conclusion}

The development of novel translational research technologies and approaches is of central importance for successful CAM research [36-39]. For long, a huge disconnect has been observed between clinical and preclinical studies of CAM agents. Our rapid screening methods provide evidence that some traditional herbs have a potential antilithic effect. These useful crude extracts can be further studied using other animal or human models to verify their effects, which have been recorded in TCM books.

\section{Conflict of Interests}

The authors declare that they have no conflict of interests regarding the publication of this paper.

\section{Acknowledgments}

This work was supported by China Medical University (CMU) and Hospital (CMU97-CMC-003 and DMR-103046), CMU under the Aim for Top University Plan of the Taiwan Ministry of Education, Taiwan Ministry of Science and Technology (NSC102-2314-B-039-025), and in part by the Taiwan Ministry of Health and Welfare Clinical Trial and Research Center of Excellence (DOH102-TD-B-111-004). San-Yuan Wu and Yung-Hsiang Chen contributed equally to this study. The authors thank Professor Mohamed Eddouks and the anonymous reviewer for his/her constructive comments, which helped them to improve the paper. The authors also thank Dr. Tin-Yun Ho for kindly providing the Chinese herbal medicines used in this study.

\section{References}

[1] A. Premgamone, P. Sriboonlue, S. Maskasem, W. Ditsataporncharoen, and B. Jindawong, "Orthosiphon versus placebo in nephrolithiasis with multiple chronic complaints: a randomized control trial," Evidence-Based Complementary and Alternative Medicine, vol. 6, no. 4, pp. 495-501, 2009.

[2] J. Prywer and A. Torzewska, "Effect of curcumin against proteus mirabilis during crystallization of struvite from artificial urine," Evidence-Based Complementary and Alternative Medicine, vol. 2012, Article ID 862794, 7 pages, 2012.

[3] R. B. de Oliveira, E. B. Coelho, M. R. Rodrigues et al., "Effect of the Copaifera langsdorffii Desf. leaf extract on the ethylene glycol-induced nephrolithiasis in rats," Evidence-Based Complementary and Alternative Medicine, vol. 2013, Article ID 131372, 10 pages, 2013. 
[4] A. L. Shirfule, V. Racharla, S. S. Qadri, and A. L. Khandare, "Exploring antiurolithic effects of gokshuradi polyherbal ayurvedic formulation in ethylene-glycol-induced urolithic rats," Evidence-Based Complementary and Alternative Medicine, vol. 2013, Article ID 763720, 9 pages, 2013.

[5] L. M. Sun, C. L. Lin, Y. J. Chang et al., "Urinary tract stone raises subsequent risk for urinary tract cancer: a population-based cohort study," BJU International, vol. 112, no. 8, pp. 1150-1155, 2013.

[6] K. J. Lin, P. H. Lin, S. H. Chu et al., "The impact of climate factors on the prevalence of urolithiasis in Northern Taiwan," Biomed Journal, vol. 37, no. 1, pp. 24-30, 2014.

[7] A. Ramello, C. Vitale, and M. Marangella, "Epidemiology of nephrolithiasis," Journal of Nephrology, vol. 13, supplement 3, pp. S45-S50, 2000.

[8] Y. Chen, C. Ho, L. Chen, S. Hsu, and W. Chen, "Wu-Ling-San formula inhibits the crystallization of calcium oxalate in vitro," American Journal of Chinese Medicine, vol. 35, no. 3, pp. 533-541, 2007.

[9] C.-H. Tsai, Y.-C. Chen, L.-D. Chen et al., "A traditional Chinese herbal antilithic formula, Wulingsan, effectively prevents the renal deposition of calcium oxalate crystal in ethylene glycolfed rats," Urological Research, vol. 36, no. 1, pp. 17-24, 2008.

[10] C. H. Tsai, T. C. Pan, M. T. Lai et al., "Prophylaxis of experimentally induced calcium oxalate nephrolithiasis in rats by Zhulingtang, a traditional Chinese herbal formula," Urologia Internationalis, vol. 82, no. 4, pp. 464-471, 2009.

[11] W. Lin, M. Lai, H. Chen et al., "Protective effect of Flos carthami extract against ethylene glycol-induced urolithiasis in rats," Urological Research, vol. 40, no. 6, pp. 655-661, 2012.

[12] E. Lin, L. Ho, M. S. Lin, M. H. Huang, and W. C. Chen, "WuLing-San formula prophylaxis against recurrent calcium oxalate nephrolithiasis-a prospective randomized controlled trial," African Journal of Traditional, Complementary, and Alternative Medicines, vol. 10, no. 5, pp. 199-209, 2013.

[13] R. Miyaoka and M. Monga, "Use of traditional chinese medicine in the management of urinary stone disease," International Braz J Urol, vol. 35, no. 4, pp. 396-405, 2009.

[14] M. Yin, "Development of natural antitumor agents," BioMedicine, vol. 3, no. 3, article 105, 2013.

[15] C. Tsai, H. Chen, L. Sheen, and C. Lii, "Garlic: health benefits and actions," BioMedicine, vol. 2, no. 1, pp. 17-29, 2012.

[16] W. Liao and F. Tsai, "Personalized medicine: a paradigm shift in healthcare," BioMedicine, vol. 3, no. 2, pp. 66-72, 2013.

[17] Y. Chen, H. Liu, H. Chen et al., "Ethylene glycol induces calcium oxalate crystal deposition in Malpighian tubules: a Drosophila model for nephrolithiasis/urolithiasis," Kidney International, vol. 80, no. 4, pp. 369-377, 2011.

[18] W. C. Chen, W. Y. Lin, H. Y. Chen et al., "Melamine-induced urolithiasis in a Drosophila model," Journal of Agricultural and Food Chemistry, vol. 60, no. 10, pp. 2753-2757, 2012.

[19] C.-Y. Ho, Y.-H. Chen, P.-Y. Wu et al., "Effects of commercial citrate-containing juices on urolithiasis in a Drosophila model," Kaohsiung Journal of Medical Sciences, vol. 29, no. 9, pp. 488493, 2013.

[20] F. Knauf and P. A. Preisig, "Drosophila: a fruitful model for calcium oxalate nephrolithiasis," Kidney International, vol. 80, no. 4, pp. 327-329, 2011.

[21] D. Assimos, "Re: ethylene glycol induces calcium oxalate crystal deposition in malpighian tubules: a drosophila model for nephrolithiasis/urolithiasis," The Journal of Urology, vol. 187, no. 4, pp. 1299-1300, 2012.
[22] T. Hirata, P. Cabrero, D. S. Berkholz et al., "In vivo Drosophilia genetic model for calcium oxalate nephrolithiasis," American Journal of Physiology: Renal Physiology, vol. 303, no. 11, pp. F1555-F1562, 2012.

[23] J. Miller, T. Chi, P. Kapahi et al., "Drosophila melanogaster as an emerging translational model of human nephrolithiasis," Journal of Urology, vol. 190, no. 5, pp. 1648-1656, 2013.

[24] H. Chen, W. Lin, Y. Chen, W. Chen, F. Tsai, and C. Tsai, "Matrix metalloproteinase- 9 polymorphism and risk of pelvic organ prolapse in Taiwanese women," European Journal of Obstetrics Gynecology and Reproductive Biology, vol. 149, no. 2, pp. 222224, 2010.

[25] C. Liang, S. Wang, Y. Chen et al., "Viscolin reduces VCAM-1 expression in TNF- $\alpha$-treated endothelial cells via the JNK/NF$\kappa \mathrm{B}$ and ROS pathway," Free Radical Biology and Medicine, vol. 51, no. 7, pp. 1337-1346, 2011.

[26] C. Lin, Y. Lin, P. Huang, H. Tsai, and Y. Chen, "Inhibition of endothelial adhesion molecule expression by Monascus purpureus-fermented rice metabolites, monacolin $\mathrm{K}$, ankaflavin, and monascin," Journal of the Science of Food and Agriculture, vol. 91, no. 10, pp. 1751-1758, 2011.

[27] Y. W. Lin, C. Y. Huang, and Y. H. Chen, "GroEL1, a heat shock protein 60 of Chlamydia pneumoniae, impairs neovascularization by decreasing endothelial progenitor cell function," PloS ONE, vol. 8, no. 12, Article ID e84731, 2013.

[28] J. Wang, X. Li, and L. Gao, "Study on extraction process of tannins from Semen Cuscutae and their anti-papilloma activity," African Journal of Traditional, Complementary, and Alternative Medicines, vol. 10, no. 3, pp. 469-474, 2013.

[29] J. Ke and R. Duan, "Effects of flavonoids from semen cuscutae on the hippocampal-hypothalamic- pituitary-ovarian sex hormone receptors in female rats exposed to psychological stress," Clinical and Experimental Obstetrics and Gynecology, vol. 40, no. 2, pp. 271-274, 2013.

[30] H. Pan, H. Sun, and Y. Pan, "Adjuvant effect of ethanol extract of Semen Cuscutae on the immune responses to ovalbumin in mice," Journal of Ethnopharmacology, vol. 99, no. 1, pp. 99-103, 2005.

[31] Y. Sohn, H. C. Kang, K. S. Kim et al., "Protective effects of natrii sulfas on cerebral focal ischemia induced by MCAO in rats," The American Journal of Chinese Medicine, vol. 37, no. 2, pp. 273-293, 2009.

[32] S. Su, T. Wang, J. Duan et al., "Anti-inflammatory and analgesic activity of different extracts of Commiphora myrrha," Journal of Ethnopharmacology, vol. 134, no. 2, pp. 251-258, 2011.

[33] T. Shen, G. Li, X. Wang, and H. Lou, "The genus Commiphora: a review of its traditional uses, phytochemistry and pharmacology," Journal of Ethnopharmacology, vol. 142, no. 2, pp. 319-330, 2012.

[34] A. M. Tonkal and T. A. Morsy, "An update review on Commiphora molmol and related species," Journal of the Egyptian Society of Parasitology, vol. 38, no. 3, pp. 763-796, 2008.

[35] E. Y. H. Nomicos, "Myrrh: medical marvel or myth of the magi?" Holistic Nursing Practice, vol. 21, no. 6, pp. 308-323, 2007.

[36] W. Jia, M. Kohlmeier, A. Lu, and R. Zeng, "Translational research in complementary and alternative medicine," Evidence-Based Complementary and Alternative Medicine, vol. 2013, Article ID 296817, 2 pages, 2013.

[37] M. M. Pandey, S. Rastogi, and A. K. S. Rawat, "Indian traditional ayurvedic system of medicine and nutritional supplementation," Evidence-Based Complementary and Alternative Medicine, vol. 2013, Article ID 376327, 12 pages, 2013. 
[38] M. Koo, "Complementary and alternative medicine on wikipedia: opportunities for improvement," Evidence-Based Complementary and Alternative Medicine, vol. 2014, Article ID 105186, 4 pages, 2014.

[39] I. Okoronkwo, J. L. Onyia-Pat, P. Okpala, M. A. Agbo, and A. $\mathrm{Ndu}$, "Patterns of complementary and alternative medicine use, perceived benefits, and adverse effects among adult users in Enugu Urban, Southeast Nigeria," Evidence-Based Complementary and Alternative Medicine, vol. 2014, Article ID 239372, 6 pages, 2014. 


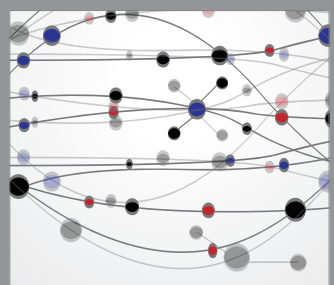

The Scientific World Journal
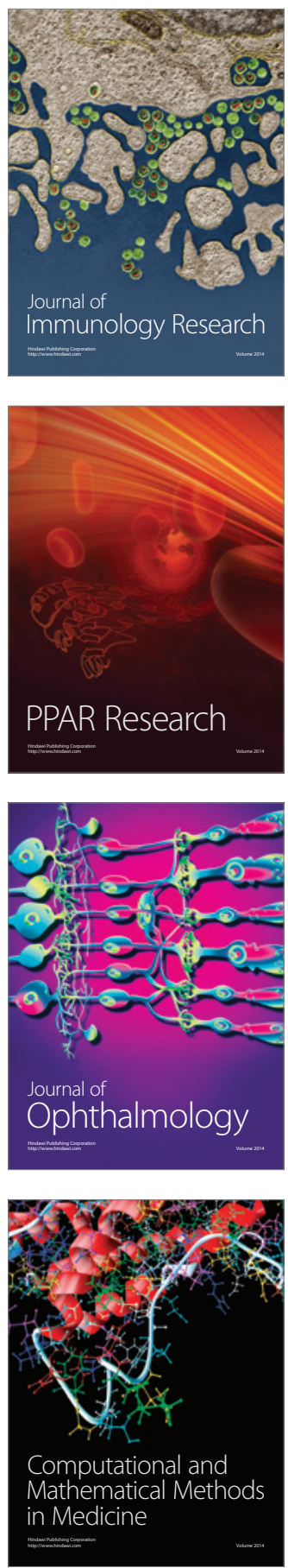

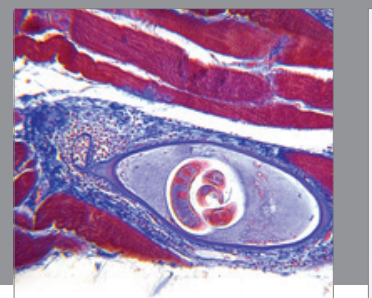

Gastroenterology

Research and Practice
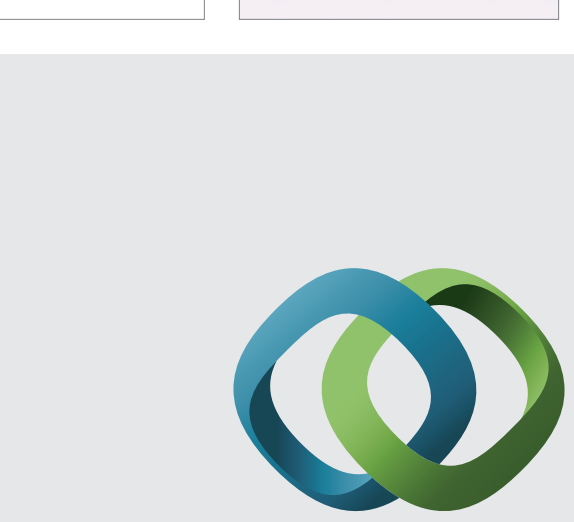

\section{Hindawi}

Submit your manuscripts at

http://www.hindawi.com
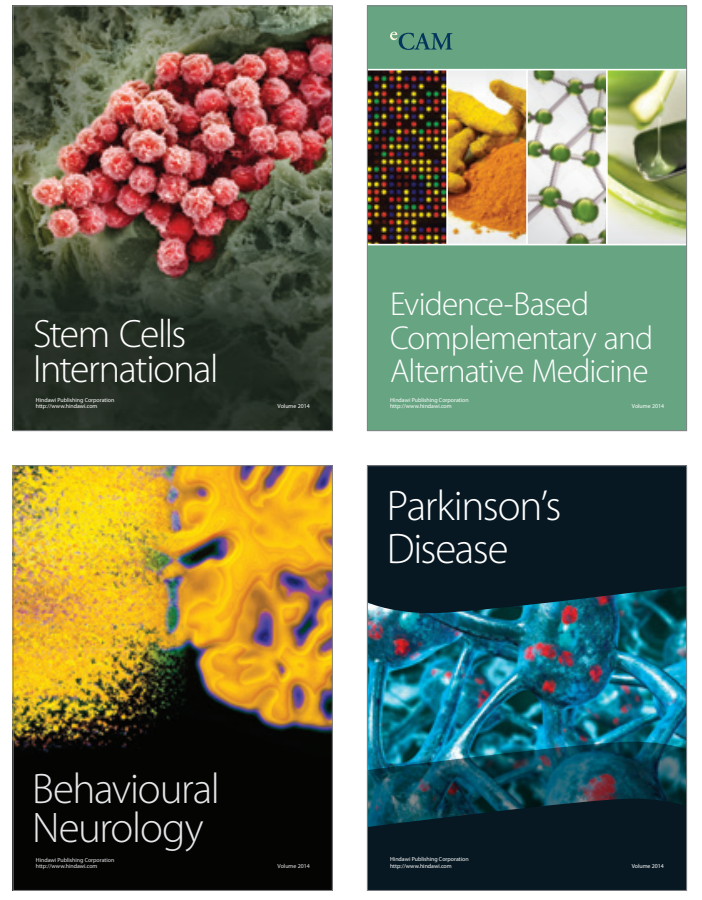
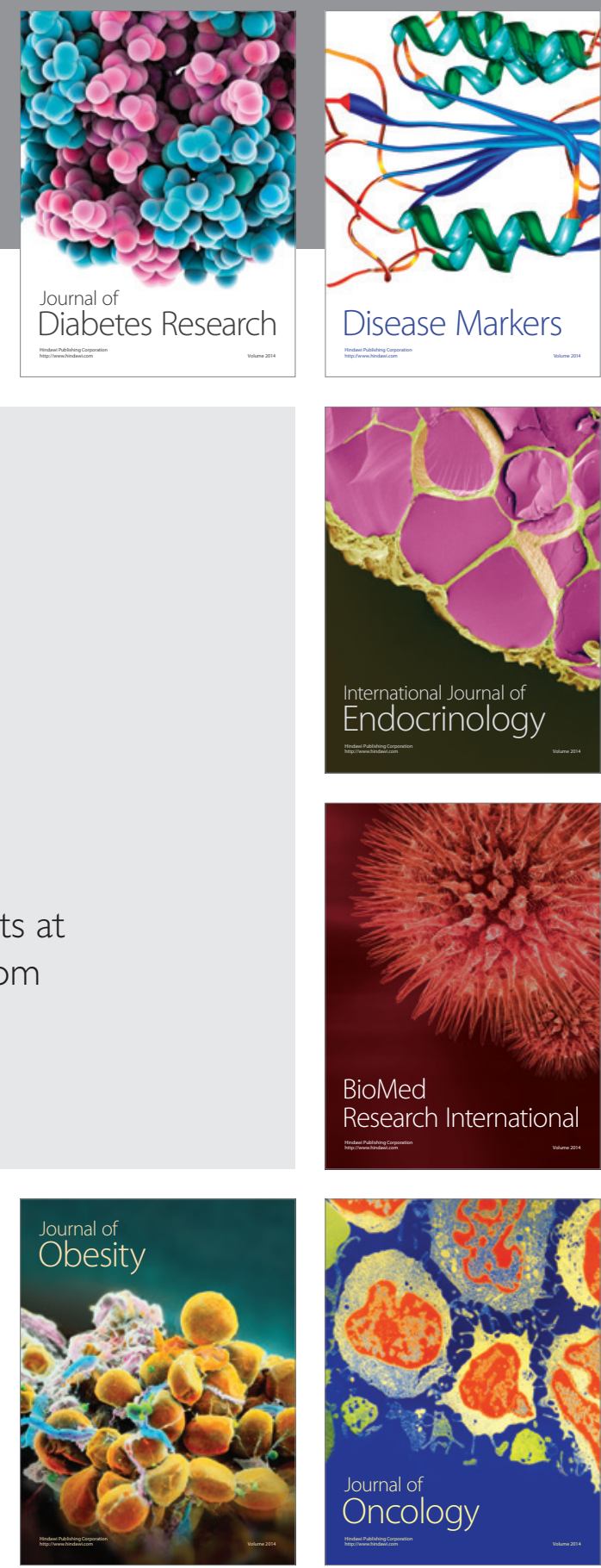

Disease Markers
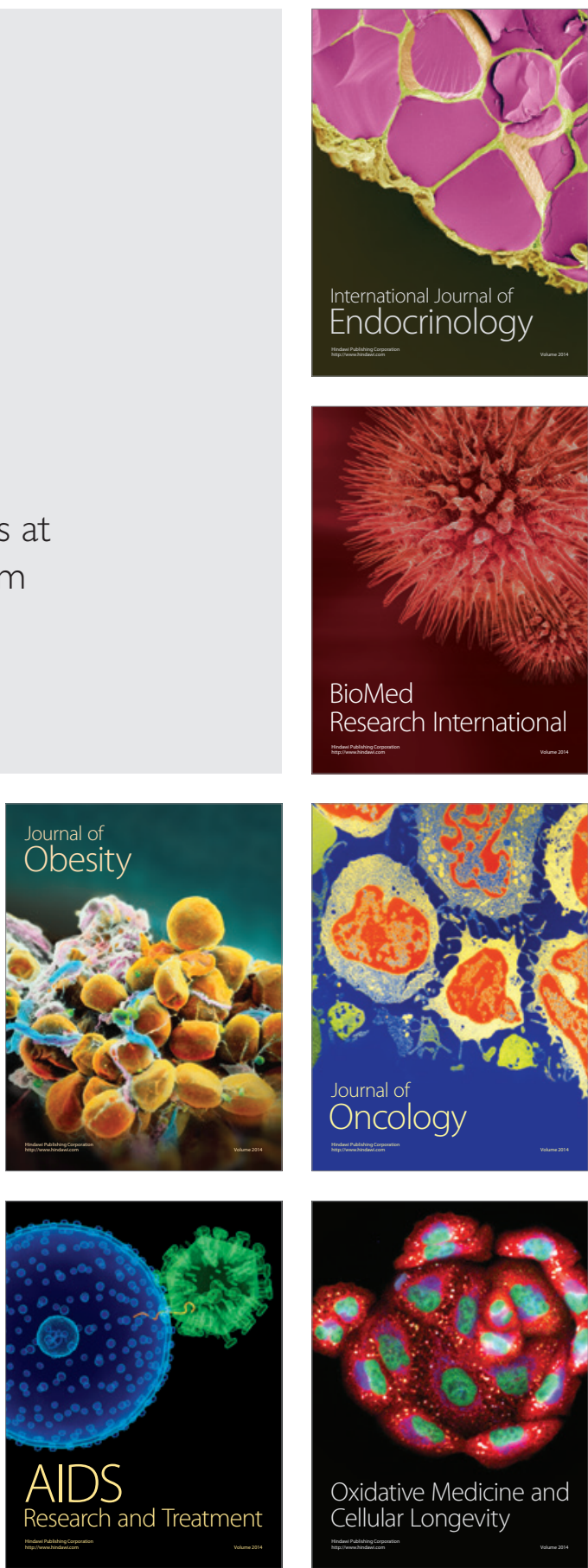